\title{
AN MHD COUPLE STRESS FLUID DUE TO A PERFORATED SHEET UNDERGOING LINEAR STRETCHING WITH HEAT TRANSFER
}

\author{
U.S. Mahabaleshwar ${ }^{1 *}$, I.E. Sarris ${ }^{2}$, A.A. Hill ${ }^{3}$, Giulio Lorenzini ${ }^{4}$ \\ \& Ioan Pop ${ }^{5}$ \\ ${ }^{1}$ Department of Mathematics, Government First Grade College for Women, Hassan -573 201, \\ INDIA \\ ${ }^{2}$ Department of Energy Technology, Technological \& Educational Institute of Athens, \\ 17 Ag. Spyridona Str., 12210 Athens, GREECE \\ ${ }^{3}$ Department of Biological, Biomedical and Analytical Sciences, University of the West of \\ England, Bristol BSI6 1QY, UNITED KINGDOM \\ ${ }^{4}$ Department of Industrial Engineering, University of Parma, , Parco Area delle Scienze 181/A \\ 43124 Parma, ITALY \\ ${ }^{5}$ Department of Mathematics, Faculty of Mathematics and Computer Science, Babeş-Bolyai \\ University, 400084 Cluj-Napoca, ROMANIA,
}

\begin{abstract}
We investigate an MHD couple stress liquid due to a perforated sheet undergoing linear stretching with radiation. The liquid is initially at rest with its activity is restricted by pulling the two sheet ends with parallel and identical forces. The consequential movement of the or else quiescent fluid is consequently generated exclusively by the stirring plate that develops a linearly varied speed with the distance from the slit. In addition to fluid flow, heat transfer with two cases of different boundary conditions from the sheet is considered, the first with prescribed surface temperature and, the second with prescribed heat flux. The arising set of non-linear coupled nonlinear partial differential equations is rehabilitated into non-linear ordinary differential equations and then exact expressions are derived for velocity and by means of a power series method with Kummer's confluent hyper-geometric functions for temperature.
\end{abstract}

KEYWORDS: Exact solution, MHD, radiation, stretching sheet, heat transfer, couple stress fluid. 


\section{Nomenclature}
$A, B, D \quad$ constants
$C_{p} \quad$ constant pressure $\left[\mathrm{W} \mathrm{kg}^{-1} \mathrm{~K}^{-1}\right]$
c stretching rate $\left[\mathrm{s}^{-1}\right]$
$C \quad\left(=\frac{c \eta_{0}}{\rho v^{2}}\right)$ couple stress parameter
$C_{1} \quad$ streamline constants
f similarity variable
${ }_{1} F_{1} \quad(=\mathrm{F}[\mathrm{a}, \mathrm{b}, \mathrm{z}])$ Kummers' expression
${ }_{2} F_{1} \quad(=\mathrm{F}[\mathrm{a}, \mathrm{b}, \mathrm{c}, \mathrm{z}])$ Kummers' expression
$g \quad\left(=\frac{T-T_{\infty}}{T_{w}-T_{\infty}}\right)$ for the PHF case
$H_{0} \quad$ magnetic field $\left[\mathrm{w} \mathrm{m}^{-2}\right]$
$k \quad$ conductivity $\left[\mathrm{W} \mathrm{kg}^{-1} \mathrm{~K}^{-1}\right]$
$k^{*} \quad$ mean absorption coefficient $\left[\mathrm{m}^{-2}\right]$
$l \quad$ length $[\mathrm{m}]$
$M \quad\left(=H_{0} \sqrt{\frac{\sigma}{c \rho}}\right)$ Hartmann number also called Chandrasekhar number
$N_{I} \quad\left(=\frac{Q^{*}}{c \rho C_{p}}\right)$ heat source/sink parameter
$N_{R} \quad\left(=\frac{16 \sigma^{*} T_{\infty}^{3}}{3 k k^{*}}\right)$ radiation number
$N u_{x} \quad\left(=\frac{x q_{w}}{k\left(T_{w}-T_{\infty}\right)}\right)$ Nusselt number 


$$
\begin{array}{ll}
P r & \left(=\frac{v}{\alpha}\right) \text { Prandtl number } \\
q_{r} & \text { radiative heat flux }\left[\mathrm{W} \mathrm{kg}^{-1} \mathrm{~m}^{-1}\right] \\
q_{w} & \text { local heat flux at the wall } \\
Q & \left(=M^{2}\right) \text { Chandrasekhar number } \\
Q_{s} & \text { heat source [W } \left.\mathrm{kg}^{-1} \mathrm{~K}^{-1} \mathrm{~m}^{-2}\right] \\
\mathrm{Re}_{x} & \left(=\frac{x U_{w}}{v}\right) \text { local Reynolds number } \\
R m & \left(=\frac{c l^{2}}{v_{m}}\right) \text { magnetic Reynolds number } \\
s & \text { wall temperature parameter } \\
T & \text { temperature }[\mathrm{K}] \\
T \infty & \text { far away from the sheet }[\mathrm{K}] \\
T_{w} & \text { wall (sheet) temperature }[\mathrm{K}] \\
U_{w} & \text { stretching velocity of the sheet } \\
u & \text { velocity component beside the sheet }\left[\mathrm{m} \mathrm{s}^{-1}\right] \\
\mathrm{v} & \text { velocity component normal to the sheet }\left[\mathrm{m} \mathrm{s}{ }^{-1}\right] \\
x & \text { x-coordinate along the sheet }[\mathrm{m}] \\
y &
\end{array}
$$

\section{Greek symbols}

$$
\begin{array}{ll}
\alpha & \left(=\frac{k}{\rho C_{P}}\right) \text { thermal diffusivity }\left[\mathrm{m}^{2} \mathrm{~s}^{-1}\right] \\
\delta & \text { thickness of boundary layer } \\
\delta_{\eta} & \left(=\delta_{\eta_{1}} \sqrt{\frac{v}{c}}\right) \text { velocity boundary layer thickness }
\end{array}
$$




\begin{tabular}{|c|c|}
\hline$\delta_{T}$ & $=\delta_{T_{1}}\left(\frac{v}{c}\right)$ thickness of thermal boundary layer \\
\hline$\delta_{\eta_{1}}$ & dimensionless velocity boundary layer thickness \\
\hline$\delta_{T_{1}}$ & dimensionless thermal boundary layer thickness \\
\hline$\eta$ & similarity variable \\
\hline$\eta_{0}$ & material constant for the couple stress fluid \\
\hline$\mu$ & limiting viscosity $\left[\mathrm{kg} \mathrm{m}^{-1} \mathrm{~s}^{-1}\right]$ \\
\hline$v$ & $\left(=\frac{\mu}{\rho}\right)$ kinematic viscosity $\left[\mathrm{m}^{2} \mathrm{~s}^{-1}\right]$ \\
\hline$v_{\mathrm{m}}$ & magnetic permeability \\
\hline$v^{\prime}$ & $\left(=\frac{\eta_{0}}{\rho}\right)$ couple stress viscosity $\left[\mathrm{m}^{2} \mathrm{~s}^{-1}\right]$ \\
\hline$\rho$ & density $\left[\mathrm{kg} \mathrm{m}^{-3}\right]$ \\
\hline$\psi$ & stream function $\left[\mathrm{m}^{2} \mathrm{~s}^{-1}\right]$ \\
\hline$\sigma$ & electrical conductivity $\left[\mathrm{mho} \mathrm{m}^{-1}\right]$ \\
\hline$\sigma^{*}$ & Stefan-Boltzmann constant \\
\hline$\xi$ & change of variable \\
\hline$\tau_{w}$ & wall shearing stress $\left[\mathrm{m}^{2} \mathrm{~s}^{-1}\right]$ \\
\hline$\theta$ & $\left(=\frac{T-T_{\infty}}{T_{w}-T_{\infty}}\right)$ for the PST case \\
\hline
\end{tabular}




\section{INTRODUCTION}

The theoretical fluid mechanics phenomena involving steady/unsteady laminar boundary layers be of large hypothetical furthermore convenient importance. The present problem has wide physical application in extrusion impulsively/linearly/non-linear stretching process like condensation process of aerodynamic development, cooling method of tinny sheet and in the glass, polymers and there are also several applications in biofluid dynamics, hydronautics and manufacturing(see Fisher [8]). Couple stress liquids over a linear stretching sheet has established significant concentration since of their widespread applications in the field of metallurgy. The developed of polymer fibers, by means of the dissolve whirling procedure, involves the extrusion of molten fibre through an orifice. Similar flows involving magnetic fields (magnetohydrodynamic flow) are also extremely vital technologically and applications in special areas of interest such as petroleum production and metallurgical processes can be found. Together to the flow, it is found also that the properties of the end products depend strongly lying on the speed of cooling implicated in these processes. Magnetic fields have been used already in the process of refinement of molten metals from nonmetallic inclusions, and Sarpakaya [19] was the initial examiner to investigate the MHD flows of a non-Newtonian liquid.

A widespread variety of mathematical models has been developed to reproduce the different hydrodynamic/hydromagnetic behavior of these non-Newtonian liquids. Expressive expositions of viscoelastic fluid models have been investigated by Joseph [10]. Examples of such models are the Rivlin-Ericksen second order model [15] and Siddappa and Khapate [21] and the Oldroyd model [30] see also Bhatnagar [3] where the flow of an Oldroyd-B liquid is considered, occupying the space over an elastic plate, due to the stretching of the sheet in the presence of a constant free-stream velocity. Moreover, the Johnson-Seagalman model, the upper convected 
Maxwell model, see Rao [25], Rao and Rajgopal [26] and the Walters' liquid B model [29], Siddheshwar and Mahabaleshwar [20] and Mastroberardino and Mahabaleshwar [13] have been proposed. Recently, Maxwell model and Oldroyd-B model have been used to study the flow of viscoelastic liquids on top of stretching and non stretching sheets but with no heat transfer effects involved. Together steady and unsteady flows have been presented expansively in a different variety of geometries using a wide spectrum of analytical, semi-analytical and numerical methods (see Mahabaleshwar [14], Siddheshwar and Mahabaleshwar [2005], Andersson et al. [2], Turkyilmazoglu and Pop[24] and Xu et al [31]) .

The theory of Boussinesq- Stokes suspension that displays the effect of couple stress and the constitutive equations for couple stress liquids is due to Stokes (1966). A imperative group of pupils of non-Newtonian liquid model is the couple stress replica which is a vigorous models for definite polymeric materials. Sakiadis [15-17] was the first researcher that discusses the boundary layer flow theoretically, numerically and experimentally and then his theory was extensive further by Crane [3]. He pointed out that in the polymer industry it is sometimes essential to consider a stretching plate. An analytical form was presented by Crane [3]. Crane flow was investigated by Gupta and Gupta [11] for the heat and mass transfer over a linear stretching plate in the being there of suction/injection issuing from a thin slit. A non-isothermal moving sheet was dealt with and the temperature and concentration distribution profiles for that situation were obtained. Carragher and Crane [5] analyzed the heat transfer owing to a continuous stretching plate. Pavlov [25] obtainable an correct resemblance explanation of the magnetohydrodynamics. The heat and mass transfer over a stretching sheet with or without suction/blowing and with/without magnetic field is studied by other researchers (Fox et al. [8], Chen and Char [6], Mahabaleshwar [14], etc.) by taking different situations. 
All the above mentioned researchers restricted their analyses to viscous flows. Many unexplored aspects of the linear stretching sheet problem are unearthed by the present study which is a overview of the works of Crane [7] and Pavlov [25]. Motivated by every person these investigates we intend to examine an MHD couple stress fluid due to a perforated sheet undergoing linear stretching with heat transfer. Furthermore for MHD flows, the effects of heat source/sink, radiation, wall temperature and magnetic field on couple stress fluid flow over a stretching sheet are discussed. Presents consequences have potential scientific applications in fluid based systems concerning stretchable supplies, in polymer extrusion process and similar problems.

\section{MATHEMATICAL FORMULATION AND SOLUTION}

Let us consider an MHD couple stress liqid due to a perforated sheet undergoing linear stretching with radiation. The two-dimensional flow of the fluid is confined to the half space $y>$ 0 above the sheet as shown in Fig.1. The plate is being stretched with a speed proportional to the distance from the origin, at $x=0$, by applying two equal and opposite forces along its $x$-axis. The Reynolds number, $R_{\mathrm{m}}$, is assumed small $\left(R_{\mathrm{m}}<<1\right)$ which implies that negligible magnetic field is induced in comparison to the external one. The low magnetic Reynolds number approximation results as a linear damping Lorentz force expression in the linear momentum boundary layer equation. As the cold or the hot fluid extrudes from the slit, heat is transferred volumetrically and by radiation in addition to the usual conduction and convection mechanisms.

\subsection{Governing equations}

The continuity equation, linear momentum boundary layer expressions for a steady liquid flow past a stretching plate are given by Stokes [22] where the couple stress fluid model is based on the presumption that the fluent medium can sustain couple stresses. The assumptions are such 
that Siddheshwar and Mahabaleshwar [20] facilitate the use of laminar boundary layer approximations. The leading expressions for conservation of mass, linear momentum and energy equation with the couple stress term, the Lorentz force term, the heat resource/sink and the radiation terms are given by:

$$
\begin{aligned}
& \frac{\partial u}{\partial x}+\frac{\partial v}{\partial y}=0 \\
& u \frac{\partial u}{\partial x}+v \frac{\partial u}{\partial y}=v \frac{\partial^{2} u}{\partial y^{2}}-\frac{\eta_{0}}{\rho} \frac{\partial^{4} u}{\partial y^{4}}-\frac{\sigma H_{o}^{2}}{\rho} u \\
& u \frac{\partial T}{\partial x}+v \frac{\partial T}{\partial y}=\alpha \frac{\partial^{2} T}{\partial y^{2}}+\frac{Q_{s}}{\rho C_{p}}\left(T-T_{\infty}\right)-\frac{1}{\rho C_{p}} \frac{\partial q_{r}}{\partial y},
\end{aligned}
$$

where, $u$ and $\mathrm{v}$ represents the velocities components in the $\mathrm{x}$ and $\mathrm{y}$ directions, respectively, $T$ represents temperature, $\eta_{0}$ is the material constant of the couple stress fluid, $\rho$ the density, $\sigma$ the electrical conductivity, $\alpha$ the thermal diffusivity, $Q_{s}$ is the volumetric heat generation ( $\left.Q_{s}>0\right)$ or absorption $\left(Q_{s}<0\right)$ source, and $C_{p}$ is the specific heat. The pressure gradient term as usual is negligible in these problems. By using the Rosseland approximation for radiation (see Brewster [4], Siddheshwar and Mahabaleshwar [2005],), the radiative heat flux $q_{r}$ can be expressed as:

$$
q_{r}=-\frac{4 \sigma^{*}}{3 k^{*}} \frac{\partial\left(T^{4}\right)}{\partial y}
$$

Using Taylor series expansions about $T_{\infty}$ the quantity $T^{4}$ can be expressed as:

$T^{4}=T_{\infty}^{4}+4 T_{\infty}^{3}\left(T-T_{\infty}\right)+6 T_{\infty}^{2}\left(T-T_{\infty}\right)^{2}+\cdots$. 
Omitting higher-order expressions of $\left(T-T_{\infty}\right)$ in the above expression away from the first degree, $T^{4}$ can be approximated by:

$T^{4} \cong-3 T_{\infty}^{4}+4 T_{\infty}^{3} T$

By employing Eqs. (4), (5) and (6), Eq. (3) becomes:

$u \frac{\partial T}{\partial x}+v \frac{\partial T}{\partial y}=\left(\alpha+\frac{16 \sigma^{*} T_{\infty}^{3}}{3 \rho C_{p} k^{*}}\right) \frac{\partial^{2} T}{\partial y^{2}}+\frac{Q^{*}}{\rho C_{p}}\left(T-T_{\infty}\right)$.

The velocity at the stretching sheet is linear in $x$ and the boundary conditions related to the flow problem are

$$
\begin{aligned}
& u(x, 0)=U_{x}(x)=c x, v(x, 0)=0, \frac{\partial^{2} u}{\partial y^{2}} \text { is finite }, T=T_{w}(x, 0) \\
& u(x, \infty) \rightarrow 0, u_{y} \rightarrow 0, \frac{\partial^{2} u}{\partial y^{2}} \rightarrow 0, \quad T(x, \infty) \rightarrow T_{\infty},
\end{aligned}
$$

where, $c$ is a specified rate of stretching constant with dimensions of inverse time, such that the position of a material point particle on the stretching sheet advances exponentially in time.

PRESCRIBED SURFACE TEMPERATURE (PST) and PRESCRIBED HEAT FLUX (PHF)

The prescribed power law surface temperature, $T_{w}$, is considered to be a power of $x$ in the form

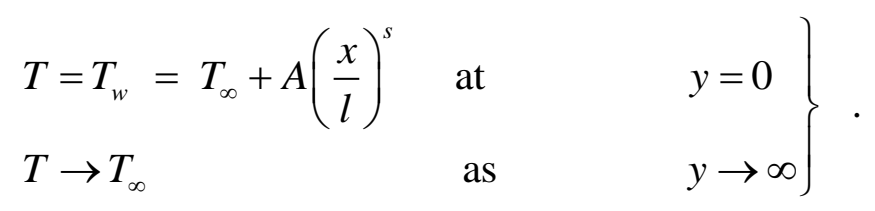


Moreover, the power law heat flux, $q_{w}$, on the wall surface is considered to be a power of $\mathrm{x}$ in the form

$$
\left.\begin{array}{ll}
-k \frac{\partial T}{\partial y}=q_{w}=D\left(\frac{x}{l}\right)^{s} & \text { at } \quad y=0 \\
T \rightarrow T_{\infty} & \text { as } \quad y \rightarrow \infty
\end{array}\right\} .
$$

\subsection{SOLUTION OF THE LINEAR MOMENTUM EQUATION}

The fluid flow is caused solely by the stretching of the sheet, with the free stream velocity being zero. Equations (1) and (2) admit self-similar solution of the form:

$$
u=c x f_{\eta}(\eta), \quad \mathrm{v}=-\sqrt{c v} f(\eta), \quad \psi=x \sqrt{c v} f(\eta), \quad \eta=\left(\frac{c}{v}\right)^{\frac{1}{2}} y
$$

where, $\eta$ denotes the derivative with respect to $\eta$. The physical stream function is related to the axial and transverse velocities components $(u, v)$ by the standard definition $u=\partial \psi / \partial y, v=$ $-\partial \psi / \partial x$. Clearly $u$ and $v$ satisfy Eq. (1) identically, and by substituting these new variables in Eq. (2), we have

$$
C f_{\eta \eta \eta \eta \eta}^{5}-\left[f_{\eta \eta \eta}+f f_{\eta \eta}-\left(f_{\eta}\right)^{2}+Q f_{\eta}\right]=0
$$

where, $C=\frac{v^{\prime} c}{v}$ is the dimensionless couple stress parameter, $v^{\prime}$ is the couple stress viscosity and $Q=\frac{\sigma H_{0}^{2}}{c \rho}$ is the Chandrasekhar number. Equation (12) is a non-linear equation with only two terms being linear. The dimensionless boundary conditions for $f(\eta)$ can be obtained from Eqs. (8) after applying the transformations of Eqs. (11) as: 


$$
\begin{aligned}
& f(\eta)=0, \quad f_{\eta}(\eta)=1, \quad \text { at } \quad \eta=0 \\
& f_{\eta}(\eta) \rightarrow 0, \quad f_{\eta \eta}(\eta) \rightarrow 0, \quad f_{\eta \eta \eta}(\eta) \rightarrow 0, \quad \text { as } \quad \eta \rightarrow \infty \text {. }
\end{aligned}
$$

Investigating the nature of $f(\eta)$ at $\eta=0$ and as $\eta \rightarrow \infty$, seems appropriate to assume the following form for $f(\eta)$ :

$f(\eta)=A_{1}+B_{1} \operatorname{Exp}[-\beta \eta]$

With the help of the boundary conditions in Eqs. (13), $A_{1}$ and $B_{1}$ can be calculated and the solution turns out to be (see Crane [7], Pavlov [25] and Siddheshwar \& Mahabaleshwar [20] for a similar analysis):

$$
f(\eta)=\frac{1-e^{-\beta \eta}}{\beta}, \quad \beta>0
$$

where, the constant $\beta$ is determined from the solution of biquadratic equation:

$$
C\left(\beta^{2}\right)^{2}-\beta^{2}+(1+Q)=0
$$

Equation (16) is biquadratic and can have four solutions, which it follows that:

$$
\beta=\sqrt{\frac{1+\sqrt{1-4 C(1+Q)}}{2 C}}>0 .
$$

In this case, there is only one positive root to equation.

\subsection{SOLUTION OF THE HEAT EQUATION UNDER PST}

In the case of PST, the non-dimensional temperature $\theta(\eta)$ is defined as

$$
\theta(\eta)=\frac{T-T_{\infty}}{T_{w}-T_{\infty}}
$$

where 
$T-T_{\infty}=A\left(\frac{x}{l}\right)^{s} \theta(\eta)$, and $T_{w}-T_{\infty}=A\left(\frac{x}{l}\right)^{s}$

Substitution of Eqs. (18) and (19) in the energy equation, Eq. (7), leads to the subsequent equation:

$\left(1+N_{R}\right) \theta_{\eta \eta}(\eta)+f(\eta) \operatorname{Pr} \theta_{\eta}(\eta)-\operatorname{Pr}\left(s f_{\eta}(\eta)-N_{I}\right) \theta(\eta)=0$

where, $N_{R}$ is the radiation number, $\operatorname{Pr}$ is the Prandtl number, and $N_{I}$ is the heat source/sink parameter.

The dimensionless thermal boundary conditions of $\theta$ can be obtained from Eqs. (9) and (18) as $\left.\begin{array}{lll}\theta=1 & \text { at } & \eta=0 \\ \theta \rightarrow 0 & \text { as } & \eta \rightarrow \infty\end{array}\right\}$

The boundary conditions of Eqs. (21) are linear in $\theta$ and have one exact solution in expressions of the Kummer's confluent hypergeometric function $\mathrm{F}[\mathrm{a}, \mathrm{b}, \mathrm{c} \mathrm{z}]={ }_{2} \mathrm{~F}_{1}$ (see Abramowitz and Stegun [1], Chapter 13) by using the transformation:

$\xi=-R e^{-\beta \eta}$

where, $\mathrm{R}=\frac{P r}{\beta^{2}}$.

Substituting Eq. (22) into Eq. (20), we get

$\left(1+N_{R}\right) \xi \theta_{\xi \xi}(\xi)+\left[4\left(1+N_{R}\right)-R-\xi\right] \theta_{\xi}(\xi)+\left(s+\frac{R N_{I}}{\xi}\right) \theta(\xi)=0$,

where, subscripts $\xi$ denotes differentiation

The boundary conditions of Eq. (21), in terms of $\xi$ translate to

$\theta(\xi=-R)=1 \quad$ and $\quad \theta(0)=0$ 
A solution of the homogeneous Eq. (23) by power series method is assumed as $\theta(\xi)=\sum_{i=0}^{\infty} \alpha_{i} \xi^{k+i}$, where, $\alpha_{i}{ }^{\prime} s$ are arbitrary constants and $k$ is the constant to be determined. The assumed solution is substituted in Eq. (23) and the coefficient of each degree term in $\xi$ is equated to zero. The solution of Eq. (23) fulfilling the conditions (24) interms of Kummer's function (see Abramowitz and Stegun [1]) is:

$\theta(\xi)=\left(\frac{-\xi}{R}\right)^{\left(\frac{k_{1}+k_{2}}{2}\right)} \frac{{ }^{1} F_{1}\left[\frac{k_{1}+k_{2}-s-2}{2}, k_{1}+1, \xi\right]}{{ }^{1} F_{1}\left[\frac{k_{1}+k_{2}-s-2}{2}, k_{1}+1,-R\right]}$,

where, $k_{1}=\left(\frac{\operatorname{Pr}}{\beta^{2}\left(1+N_{R}\right)}\right)$ and $k_{2}=\sqrt{\left(\frac{\operatorname{Pr}}{\beta^{2}\left(1+N_{R}\right)}\right)^{2}-4 N_{I}\left(\frac{\operatorname{Pr}}{\beta^{2}\left(1+N_{R}\right)}\right)}$

The solution of Eq. (25) can be written in terms of $\eta$ as

$\theta(\eta)=e^{-\beta\left(\frac{k_{1}+k_{2}}{2}\right) \eta} \times \frac{1_{1}\left[\frac{k_{1}+k_{2}-s-2}{2}, k_{2}+1,-\mathrm{Re}^{-\beta \eta}\right]}{1_{1}\left[\frac{k_{1}+k_{2}-s-2}{2}, k_{2}+1,-R\right]}$.

The non dimensional wall temperature gradient as derived from Eq. (26) is

$$
\theta_{\eta}(0)=\frac{R \beta}{2}\left(\frac{k_{1}+k_{2}-s-2}{k_{2}+1}\right)\left\{\frac{{ }^{1} F_{1}\left[\frac{k_{1}+k_{2}-s-1}{2}, k_{2}+2,-R\right]}{{ }^{1} F_{1}\left[\frac{k_{1}+k_{2}-s-2}{2}, k_{2}+1,-R\right]}\right\}-\beta\left(\frac{k_{1}+k_{2}}{2}\right)
$$

The expressions in Eq. (26) and Eq. (27) are presented for several values of the parameters' $C, Q$, $N_{R}, N_{I}, \operatorname{Pr}$, and $s$ and the results are discussed after the next section. 


\subsection{SOLUTION OF THE HEAT EQUATION UNDER PHF}

In the case of a wall heat flux boundary condition is given, a non-dimensional temperature $g(\eta)$ can be defined as:

$k \frac{\partial T}{\partial y}=D\left(\frac{x}{l}\right)^{s}$ at $y=0 \quad$ and $g(\eta)=\frac{T-T_{\infty}}{\frac{D}{k}\left(\frac{x}{l}\right)^{s} \sqrt{\frac{\nu}{c}}}$

$T \rightarrow T_{\infty} \quad$ as $y \rightarrow \infty$

where,

$$
T-T_{\infty}=\frac{D}{k}\left(\frac{x}{l}\right)^{s} \sqrt{\frac{v}{c}} g(\eta) .
$$

For clarity reasons, the symbol $g(\eta)$ is selected in Eq. (28) for the notation of the temperature variable for the prescribed wall heat flux case, although it corresponds to the same physical temperature as the variable $\theta(\eta)$ defined for the PST case in Eq. (18). Substitution of Eq. (28) in the energy equation, Eq. (7), leads to the subsequent equation:

$$
\left(1+N_{R}\right) g_{\eta \eta}(\eta)+\operatorname{Pr} f(\eta) g_{\eta}(\eta)-\operatorname{Pr}\left(s f_{\eta}(\eta)-N_{I}\right) g(\eta)=0
$$

The thermal boundary conditions can be transformed in terms of $g$ from Eqs. (10) and (28) as:

$$
g_{\eta}(0)=-1 \quad \text { and } \quad g(\infty)=0 \text {, }
$$

Substituting Eq. (22) into Eqs. (30) and (31), we get 
$\left(1+N_{R}\right) \xi g_{\xi \xi}(\xi)+\left[4\left(1+N_{R}\right)-R-\xi\right] g_{\xi}(\xi)+\left(s+\frac{R N_{I}}{\xi}\right) g(\xi)=0$

$g_{\xi}(-R)=-\frac{1}{R \beta}$ and $g(0)=0$

where, $\xi$ subscripts denotes differentiation. Equation (32) is a confluent hypergeometric equation and the solution for $g$ satisfying Eq. (33) is obtained in terms of Kummer's function (see Abramowitz and Stegun [1]) as:

$$
\begin{gathered}
g(\xi)=\left[\frac{1}{\beta}\right]\left\{\left(\frac{k_{1}+k_{2}}{2}\right)^{1} F_{1}\left[\frac{k_{1}+k_{2}-s-2}{2}, k_{2}+1,-R\right]-R^{1} \dot{F}_{1}\left[\frac{k_{1}+k_{2}-s-2}{2}, k_{2}+1,-R\right]\right\}^{-1} \\
\left(\frac{-\xi}{R}\right)^{\left(\frac{k_{1}+k_{2}}{2}\right){ }^{1} F_{1}\left[\frac{k_{1}+k_{2}-s-2}{2}, k_{2}+1,-\xi\right],}
\end{gathered}
$$

where, the function $\dot{F}$ satisfies the relationship ${ }^{1} \dot{F}_{1}[a, b, z]=\frac{a}{b} F[a+1, b+1, z]$ and the other terms are as defined earlier. In terms of $\eta$, the expression for $g$ is

$$
\begin{gathered}
g(\eta)=\left[\frac{1}{\beta}\right]\left\{\frac{k_{1}+k_{2}}{2}{ }^{1} F_{1}\left[\frac{k_{1}+k_{2}-s-2}{2}, k_{2}+1,-R\right]-R^{1} \dot{F}_{1}\left[\frac{k_{1}+k_{2}-s-2}{2}, k_{2}+1,-R\right]\right\}^{-1} \\
\operatorname{Exp}\left[-\beta\left(\frac{k_{1}+k_{2}}{2}\right) \eta\right]{ }^{1} F_{1}\left[\frac{k_{1}+k_{2}-s-2}{2}, k_{2}+1,-R \operatorname{Exp}(-\beta \eta)\right] .
\end{gathered}
$$

The wall temperature $T_{w}$ is obtained from Eq. (29) as

$T_{w}-T_{\infty}=\frac{D}{k}\left(\frac{x}{l}\right)^{s} \sqrt{\frac{v}{c}} g(0)$.

and the local heat flux can be expressed as

$$
q_{w}=-k\left(\frac{\partial T}{\partial x}\right)_{y=0}=-k A \sqrt{\frac{c}{v}}\left(\frac{x}{l}\right)^{s} g(0) .
$$


The substantial quantity of interest is the local skin friction coefficient $C_{f}$ and local Nusselt number $N u_{x}$ can be found from the subsequent definition:

$$
N u_{x}=\frac{x}{k}\left(\frac{q_{w}}{T_{w}-T_{\infty}}\right)
$$

where $q_{w}$ is the local heat flux can be expressed as

$$
q_{w}=-k\left(\frac{\partial T}{\partial y}\right)_{y=0}=-k A \sqrt{\frac{c}{v}}\left(\frac{x}{l}\right)^{s} \theta_{\eta}(0)
$$

Hence using Eq. (11), we get

$$
N u_{x}=\left\{\begin{array}{l}
-\sqrt{\operatorname{Re}_{x}} \theta_{\eta}(0) \quad \text { PST case } \\
-\sqrt{\operatorname{Re}_{x}} g_{\eta}(0) \quad \text { PHF case }
\end{array}\right.
$$

where, $\operatorname{Re}_{x}=\frac{x U_{w}}{v}$ is the local Reynolds number, and the local skin friction coefficient $C_{f}$ can be expressed by:

$$
C_{f} \sqrt{\mathrm{Re}_{x}}=f_{\eta \eta}(0)
$$

\section{RESULTS AND DISCUSSION}

The consequences from the analytical solutions of the velocity and temperature in the sheet are obtainable for all independent parameters of the couple stress fluid over the linear sheet, as derived by Eqs. (15), (26), and (35). The variations of velocity components along and in the normal direction of the sheet are presented at Figs. 2 and 3 for a range of values of $Q$ and $C$, the Chandrasekhar number and the couple stress parameter, respectively. Moreover, distributions of temperature are presented at Figs. 5 to 10 for a range of values of $\operatorname{Pr}, N_{R}, s$, and $N_{I}$, the Prandtl 
and radiation numbers, and the wall temperature and volumetric heat source/sink parameters, respectively, as well as $C$ and $Q$.

Figures 2 to 3 illustrate the two velocity profile distributions, $f_{\eta}(\eta)$ and $f(\eta)$ i.e. the velocity components $u$ and $v$ at the longitudinal $(x)$ and transverse $(y)$ directions, respectively, versus $\eta$ for various values of the Chandrasekhar number $Q$ for the constant value of $C=0.1$ (Fig. 2) and various values of the couple stress parameter $C$ for the constant value of $Q=1$ (Fig. 3). Since the present study is a generalization of the classical works of Crane [7] and Pavlov (1974) their solutions are also presented in both figures. The present results approach asymptotically the results of Crane [7] as $Q \rightarrow 0$ and $C \rightarrow 0$ and the results of Pavlov [25] as $C \rightarrow 0$, where the asymptotic flow case of $C=0$ corresponds to the Blasius solution for the flow over a flat plate. It is observed that both velocity components (transverse and longitudinal) are decreased by the increase of $Q$ and $C$ because the flow is decelerated. In the case of the magnetic field increase, the rate of transport decreases because of the flow breaking due to the Lorentz force action that opposes any fluid motion as $Q$ increases. Moreover, the fluid viscosity increases and stronger force is needed to retain the same fluid flow as $C$ increases. Since in the present work the driving force is kept constant, $C$ increase corresponds to flow deceleration in a similar to the magnetic field manner.

Based on the stream function definition, Eq. (11), and the streamline derivation as described in Kumaran and Ramanaiah [12], the streamline patters for the case $Q=1$ and $C=0.1$ are presented in Fig. 4a, while the streamlines for $\psi=1$ are drawn in Figs. $4 \mathrm{~b}$ and c for different values of $C$ and $Q$, respectively. At large distances, all streamlines are found to confined near the axis as the sheet is shrunk and as the rate of shrinking is observed to be almost 
independent of the $C$ and $Q$ magnitude for large $\xi$. This is due to the linear dependence of both parameters to the velocity, thus their influence is proportional to the small velocity magnitude. Both parameters, $Q$ and $C$, have similar effect on the flow pattern as their increase result in the momentum boundary layer thickening, Figs. $4 \mathrm{~b}$ and c, and thus most of the of the fluid is flowing closer to the $x$-axis an effect close to the so called Hartmann breaking, where the increase of the magnetic field results in narrowing the Hartmann boundary layers in the walls normal to the magnetic field. Similar to the thickness of the boundary layer, the local skin friction coefficient $C_{f}$ is also reduced by the increase of the magnitude of $C$ and $Q$ as can be seen in Table 1 for the normalized quantity $\frac{C_{f}}{\sqrt{R e_{x}}}=f_{\eta \eta}(0)$ according to Eq. (41).

Together to the flow features of the couple stress fluid, heat transfer from the sheet is also important. The effect of the Prandtl number in the temperature distribution of the sheet is presented in Fig. 5 for both cases of the different thermal boundary conditions studied here, the PST and the PHF cases with the solid lines and the dotted lines, respectively. The solution derived by Crane (1970) is also plotted for comparison. The temperature distributions, $\theta(\eta)$ for the PST case and $g(\eta)$ for the PHF one, are presented in Fig. 5 as $P r$ increases from 1 to 5 while all the other parameters are kept constant $\left(C=0.1, Q=1, N_{R}=1, N_{I}=-1\right.$ and $\left.s=-1\right)$. The increase of Prandtl number corresponds to slower rates of thermal diffusion and higher convection rates and consequently the thermal boundary layer thickness is decreased. The temperature is decreased faster as $P r$ increases and asymptotically approaches to zero in the free stream region for smaller $\eta$. The rate of temperature reduction, i.e. the heat transfer rate, is found to be higher for the PST case, however, the asymptotic temperature for large $\eta$ is approached faster for the PHF case. The reason for the turn down in the heat transfer lies in the fact that 
increasing values of $\operatorname{Pr}$ reduces thermal diffusivity thereby reducing the heat diffused away from the heated surface and in consequence increases the temperature gradient at the surface. This phenomenon leads to a smaller energy ability that reduces the thermal boundary layer thickness. The domination of convection heat transfer as $\operatorname{Pr}$ increases is also demonstrated by the increase of $\theta_{\eta}(0)$ in Table 2, i.e. the local Nusselt number, $N u_{x}$, normalized by the local Reynolds number according to Eq. (40).

In contrast to the increase of the Prandtl number, temperature distribution is decreased slower as the radiation number, $N_{R}$, is increased and thus the thermal diffusivity due to radiation of the medium increases for both the PST and PHF cases.

Fig. 6 is showed effect of radiation $N_{R}$ is increased from 0 to 4 while all the other parameters are kept constant $\left(C=0.1, Q=1, \operatorname{Pr}=1, N_{I}=-1\right.$ and $\left.s=-1\right)$. As thermal diffusion is getting more important with the increase of $N_{R}$, the thickness of the thermal boundary layer is increased and the bulk temperature of the fluid is getting higher. Thus, it turns out that the value of $N_{R}$ should be kept small in order the temperature of the system to be regulated. Moreover, in difference to the $\operatorname{Pr}$ number, the radiation number have only a minor effect on the maximum temperature of the PHF case since the rate of heat flow is affected mostly by the thermal conductivity of the medium. The secondary effect of the radiation number in the heat transfer is also obvious from the temperature distributions of both the PST and PHF cases that have similar reduction rates, almost collapse as $\eta$ increases, and approach their asymptotical values at around the same $\eta$ as well. The rate of reduction of convective heat transfer due to the increase of $N_{R}$ is also shown in the decreased values of the local Nusselt number that is presented in Table 2. 
The effect of $s$, the wall temperature parameter, in the temperature distribution is found to be only secondary and mostly local as it is varied from -3 to 3 when all the other parameters are kept constant $\left(C=0.1, Q=1, \operatorname{Pr}=1, N_{I}=-1\right.$ and $\left.N_{R}=1\right)$ as it is shown in Fig. 7. For the PHF case, the influence of $s$ is important only for $\eta<1$ while as $\eta$ is getting larger minor influence from the boundary conditions are observed. In contrast, $s$ effect is more extensive and influences the temperature distribution in all $\eta$ in the PST case, with its stronger influence to be close to the wall as it is expected. For the PST case, it is found that the increase of $s$ increase the rate of temperature reduction in a similar but slower way as the $\operatorname{Pr}$ number does for small $\eta$, while wall parameter effect is minimum in the asymptotic temperature for large $\eta$. As $s$ is increased, the temperature gradient $\theta_{\eta}(0)$ as $\eta \rightarrow 0$ is increased, Table 2, which corresponds to the local Nusselt number increase. Thus, convection heat transfer may be influenced by the thermal boundary conditions at the wall, i.e. the possible injection of heat from the boundary into the bulk of the fluid.

Figure 8 illustrates the effect of the heat source/sink parameter, $N_{I}$, in the temperature distribution for the PST and PHF cases as varied in the range between -2 and 2 when all the other parameters are kept constant $\left(C=0.1, Q=1, \operatorname{Pr}=1, N_{R}=1\right.$ and $\left.s=-1\right)$. Following its definition, $N_{I}>0$ corresponds to a heat source (generation of thermal energy) and $N_{I}<0$ to a heat sink (destruction of thermal energy). For heat source increase, $N_{I}>0$, all temperature profiles from the two cases of PST and PHF are markedly elevated due to the volumetric heat generation that increases the bulk temperature of the fluid independently of how strong convection heat transfer could be, while the reverse behavior is clearly observed for the heat sink effect as $N_{I}<0$, where heat is removed faster and the temperature distribution is reduced. 
Since the local Nusselt number is connected to the slope of the temperature as $\eta \rightarrow 0$, convection heat transfer is found from Table 2 to increase as $N_{I}<0$.

The effects from the flow parameters $Q$ and $C$ to the heat transfer are also important and presented at Figs. 9 and 10, respectively. Figure 9 illustrates the effect of Chandrasekhar number $Q$ in the distribution of the temperature profiles for the PST and PHF cases for values between 0 and 4 when all the other parameters are kept constant $\left(C=0.1, \operatorname{Pr}=1, s=-1, N_{I}=-1\right.$ and $N_{R}=$ 1). As usually in magnetoconvection, the increase of magnetic field magnitude, here the increase of $Q$, favors conduction over convection heat transfer because of the flow breaking action of the Lorentz force. Thus, the rate of heat transfer is reduced in the fluid and its bulk temperature is increased as $Q$ increases.

Finally, the effect of $C$ increase in the temperature distribution of the PST and PHF cases for the range of the couple stress parameter $C$ between 0 and 0.3 when all the other parameters are also kept constant $\left(Q=1, \operatorname{Pr}=1, s=-1, N_{I}=-1\right.$ and $\left.N_{R}=1\right)$ is shown in Fig. 10. The temperature distribution in the PST case is less affected by the increase of C, in contrast to the temperature distribution in the PHF case, however, most of the influence is concentrated as small $\eta$. As it is observed, similar to the Chandrasekhar number, the temperature of the fluid bulk is increased as the value of $\mathrm{C}$ increases and conduction heat transfer is favored. This means that as $\mathrm{C}$ is increased the thickness of the thermal boundary layer is increased and consequently, the heat transfer is reduced as the local Nusselt number (the value of $\theta_{\eta}(0)$ in Table 2) is reduced.

\section{Conclusions}

The flow and heat transfer of an incompressible MHD couple stress fluid due to a stretching sheet are presented for various independent parameters as the couple stress parameter, the Chandrasekhar number, the Prandtl number, the wall temperature parameter, the heat/sink parameters and the radiation parameter. The exact solutions of velocity and temperature 
distributions of the couple stress fluid are derived by the solution of the governing non-linear ordinary differential equations and by using a power series method with Kummer's confluent hyper-geometric functions. Heat transfer with two cases of different boundary conditions from the sheet is considered, the first with prescribed surface temperature and, the second with prescribed heat flux. The main conclusions derived from the present investigation can be listed as follows:

- The temperature increases as the Chandrasekhar number $Q$ and the heat source/sink $N_{I}$ parameter increases, but it decreases as the Prandtl number Pr increases.

- Heat source/sink and radiation number increase the thermal boundary-layer thickness.

- Increasing radiation parameter $\left(N_{R}\right)$ heat diffusion is favored and the temperature increases through the laminar boundary layer.

- The PHF boundary condition is better suited for effective cooling of the linear stretching sheet.

- The temperature distributions of the PHF cases are qualitatively similar to that of the PST cases, but quantitatively have reduced magnitude.

Presents consequences have potential scientific applications in fluid based systems concerning stretchable supplies, in polymer extrusion process and similar problems, especially in couple stress fluids.

Acknowledgements : Dr. Mahabaleshwar (USM) wishes to thank Professor Dr C. N. R. Rao FRS, Bharat Ratna , Honorable Chairman VGST, Dept. of IT, BT ST, Bangalore, Govt. of Karnataka, India, for supporting this work under Seed Money to Young Scientists for Research (\# VGST/SMYSR/GRD-304/2013-14). USM would like to acknowledge the receipt of Asia Bridge Fellowship and thanks Prof. Akira Nakayama, Shizuoka University, Japan for his hospitality. I. E. S. work is part of the Euro Fusion research activities supported by the European Commission in the framework of the Euratom-Hellenic Republic Association. 


\section{References}

[1] Abramowitz, M., Stegun F. Handbook of Mathematical Functions, (Dover, New York 1980).

[2] Andersson, H.I., Aarseth, J.B. \& Dandapat, B.S. Heat Transfer in a Liquid Film on an Unsteady Stretching Surface. International Journal of Heat and Mass Transfer, 43, 6974(2000).

[3] Bhatnar, R. Flow of an Oldroyd-B fluid due to a stretching sheet in the presence of a free stream velocity. Int. J. Nonlinear Mech. 30, 391-405 (1995).

[4] Brewster, M.Q. Thermal Radiative Transfer Properties (John Wiley \& Sons, Canada, 1992).

[5] Carragher, P. \& Crane, L. J. Heat transfer on a continuous stretching sheet, ZAMM, 62, 564, (1982).

[6] Chen, C. K. \& Char, C. K. Heat transfer on a continuous stretching surface with suction or blowing. J. Math. Anal. Appl. 135 , 568-580, (1988).

[7] Crane, L. J. Flow past a stretching plate. Z. Angew. Math. Phys. 21 645-647, (1970).

[8] Fisher E.G. Extrusion of Plastics, (3rd Edition. Newnes- Butterworld, London 1976).

[9] Fox, V. G., Ericksen, L. E. \& Fan, L. T. Heat and mass transfer on a moving continuous flat plate with suction or injection. Ind. Eng. Chem. Fund. 5, 19 (1966).

[10] Joseph, D.D. Fluid dynamics of viscoelastic liquids. (New York: Springer-Verlag,1990).

[11] Gupta, P. S. \& Gupta, A. S. Heat and mass transfer on a stretching sheet with suction or blowing. Can. J. Chem. Eng. J. 55 744-746, (1977).

[12] Kumaran V. \& Ramanaiah G. A note on the flow over a stretching sheet. Acta Mech., 119, 229 -233 (1996).

[13] Mastroberardino, A \& Mahabaleshwar, U. S. Mixed convection in viscoelastic flow due to a stretching sheet in a porous medium. Journal of Porous Media 16, 483-500, (2013).

[14] Mahabaleshwar, U. S. Linear stretching sheet problem with suction in porous medium Open Journal of Heat, Mass and Momentum Transfer. 1, 13-18, (2013).

[15] Rivlin, R.S. \& Ericksen, L. J. Stress deformation relations for isotropic materials, J. Rat. Mech. Anal.4, 323 (1955).

[15] Sakiadis, B.C. Boundary-layer behavior on continuous solid surfaces I:The boundary layer on a equations for two dimensional and axisymmetric flow. AIChE J. 7, 26-28, (1961a). 
[16] Sakiadis, B.C. Boundary-layer behavior on continuous solid surfaces II: The boundary layer on a continuous solid surface. AIChE J. 7, 221, (1961b).

[17] Sakiadis, B.C. Boundary-layer behavior on continuous solid surfaces III: The boundary layer on a continuous cylindrical surface. AIChE J. 7, 467, (1961c).

[18] Schlichting, H. Boundary layer theory. (McGraw-Hill,New York, 1968).

[19] 1Sarpakaya, T. Flow of non-Newtonian fluids in a magnetic field. AIChE J. 7 324-328, (1961).

[20] Siddheshwar, P. G. \& Mahabaleshwar, U.S. Effects of radiation and heat source on MHD flow of a viscoelastic liquid and heat transfer over a stretching sheet. Int. J. of Nonlinear Mech. 40, 807-820, (2005).

[21] Siddappa, B. \& Khapate, B.S. Rivlin-Erickson fluid flow past stretching plate, Rev Roum. Sci, Tech. Mech. Appl, 21, 497, (1975).

[22] Stokes, V. K . Couple Stresses in Fluids. Physics of Fluids. 9, 1709, (1966).

[23] Tsou, F.K. Sparrow, E.M. \& Goldstein R.J. Flow and heat transfer in the boundary layer on a continuous moving surface. Int. J. Heat and Mass Transfer. 10 219-235, (1967).

[24] Turkyilmazoglu, M. \& Pop, I. Heat and Mass Transfer of Unsteady Natural Convection Flow of Some Nano-fluids Past Avertical Infinite Flat Plate with Radiation Effect. International Journal of Heat and Mass Transfer, 59, 67-171, (2013).

[25] Pavlov, K.B. Magnetohydrodynamic flow of an incompressible viscous liquid caused by deformation of plane surface. Magnetnaya Gidrodinamica. 4, 146-147, (1974).

[25] Rao, I.J. Flow of a Johnson-Segalman fluid between rotating coaxial cylinders with and without suction, Int. J. Non-Linear Mech., 34, 63-70, (1999).

[26] Rao, I.J. \& Rajgopal, K.R. On a new interpretation of the classical Maxwell model, Mechanics Research Communications, 34, 509-514, (2007).

[27] Raptis, A. Radiation and viscoelastic flow. Int. Comm. Heat Mass Transfer. 26, 889, (1999).

[28] Raptis, A. \& Perdikis, C. Viscoelastic flow by the presence of radiation. Z. Angen. Math. Mech. 78 277, (1998).

[29] Walters, K. Non-Newtonian effects in some elastico-viscous liquids whose behavior at small rates of shear is characterized by a general linear equation of state. Q. J. Mech. and Appl. Mathematics. 15, 63-76. (1962).

[30] Oldroyd, J.G. On the formulation of rheological equations of state, Proc Roy Soc (Lond.) Ser, A. 200, 451-523. (1950). 
[31] Xu, H., Pop, I. \& You, X.C. Flow and Heat Transfer in a Nano-liquid film over an unsteady stretching surface. International Journal of Heat and Mass Transfer. 60, 64665 (2013). 


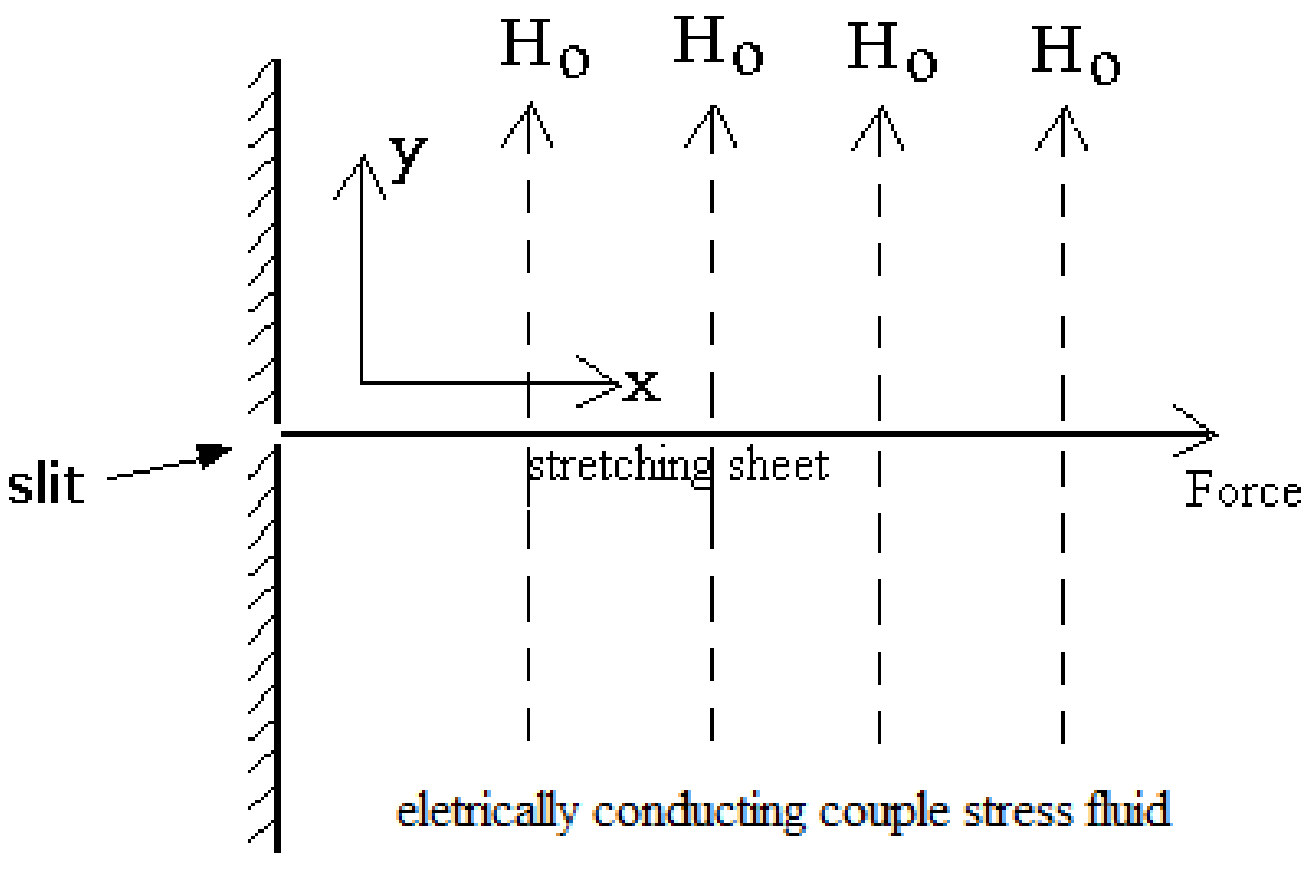

Fig.1: Schematic of the two-dimensional stretching sheet problem 


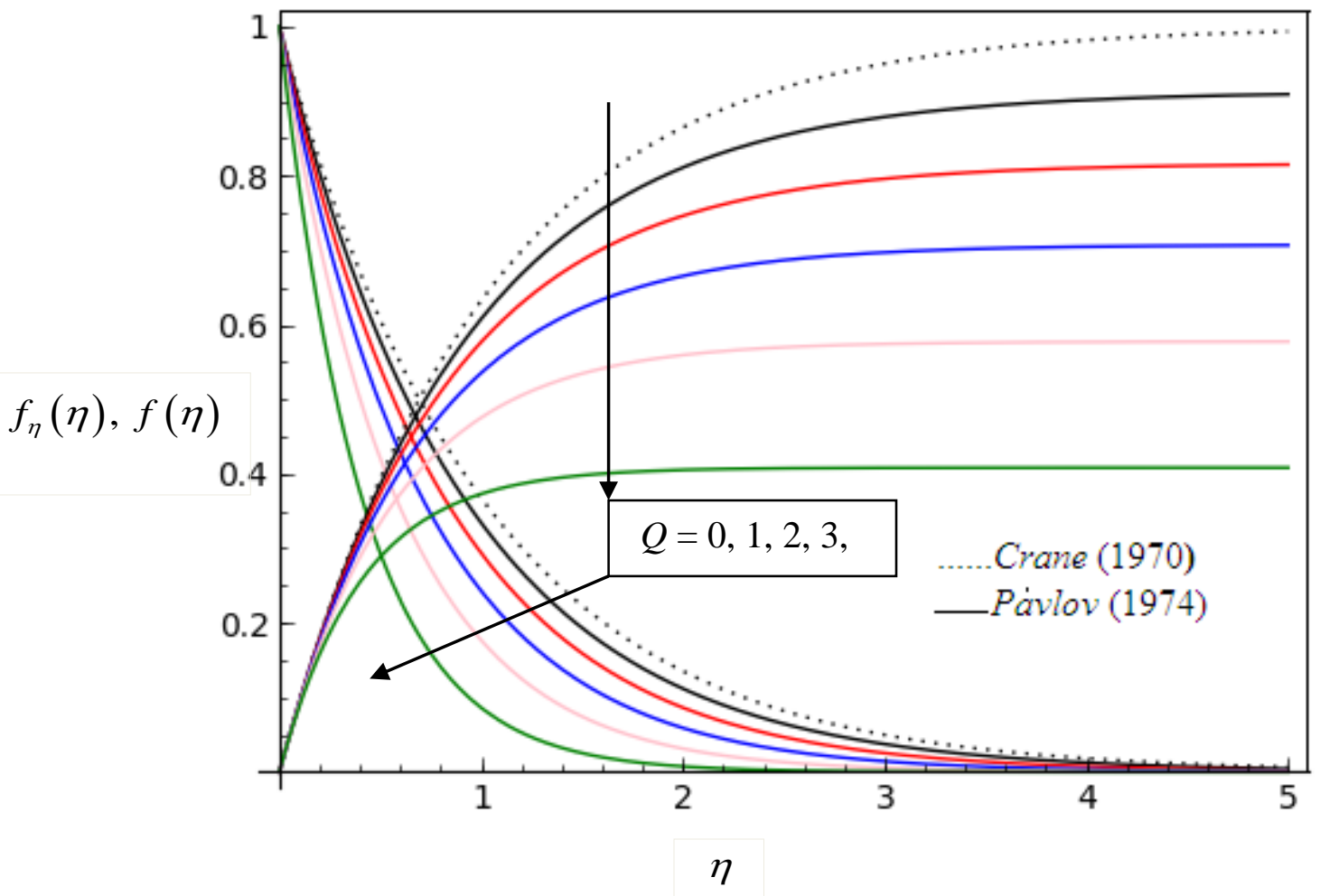

Figure 2: Plot of axial $\left(f_{\eta}(\eta)\right)$ velocity and transverse velocity $(f(\eta))$ versus $\eta$ for different values of Chandrasekhar number $Q$ with $C=0.1$. 


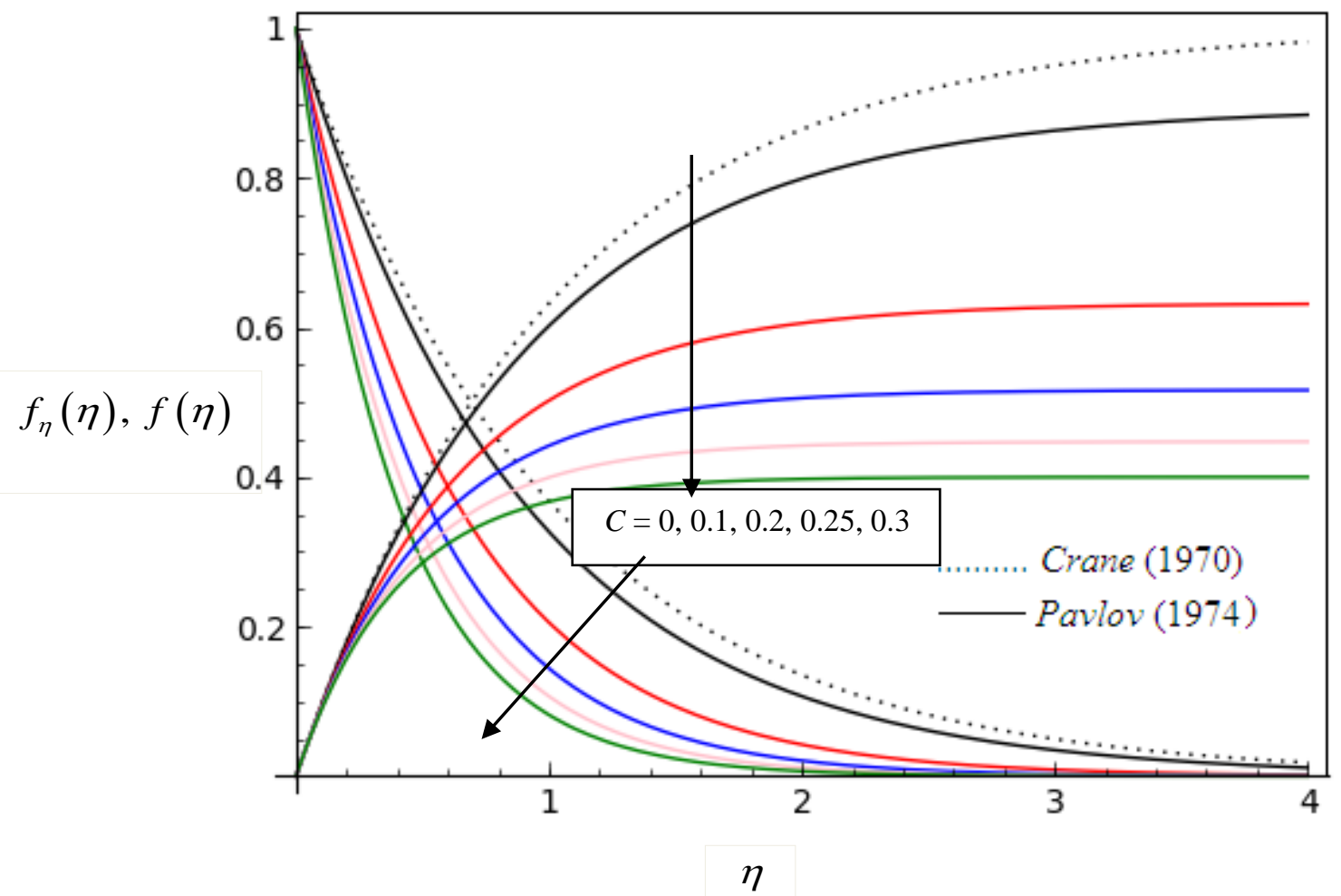

Figure 3: Plot of axial velocity and transverse velocity versus $\eta$ for different values of couple stress parameter $C$ with $Q=1$. 


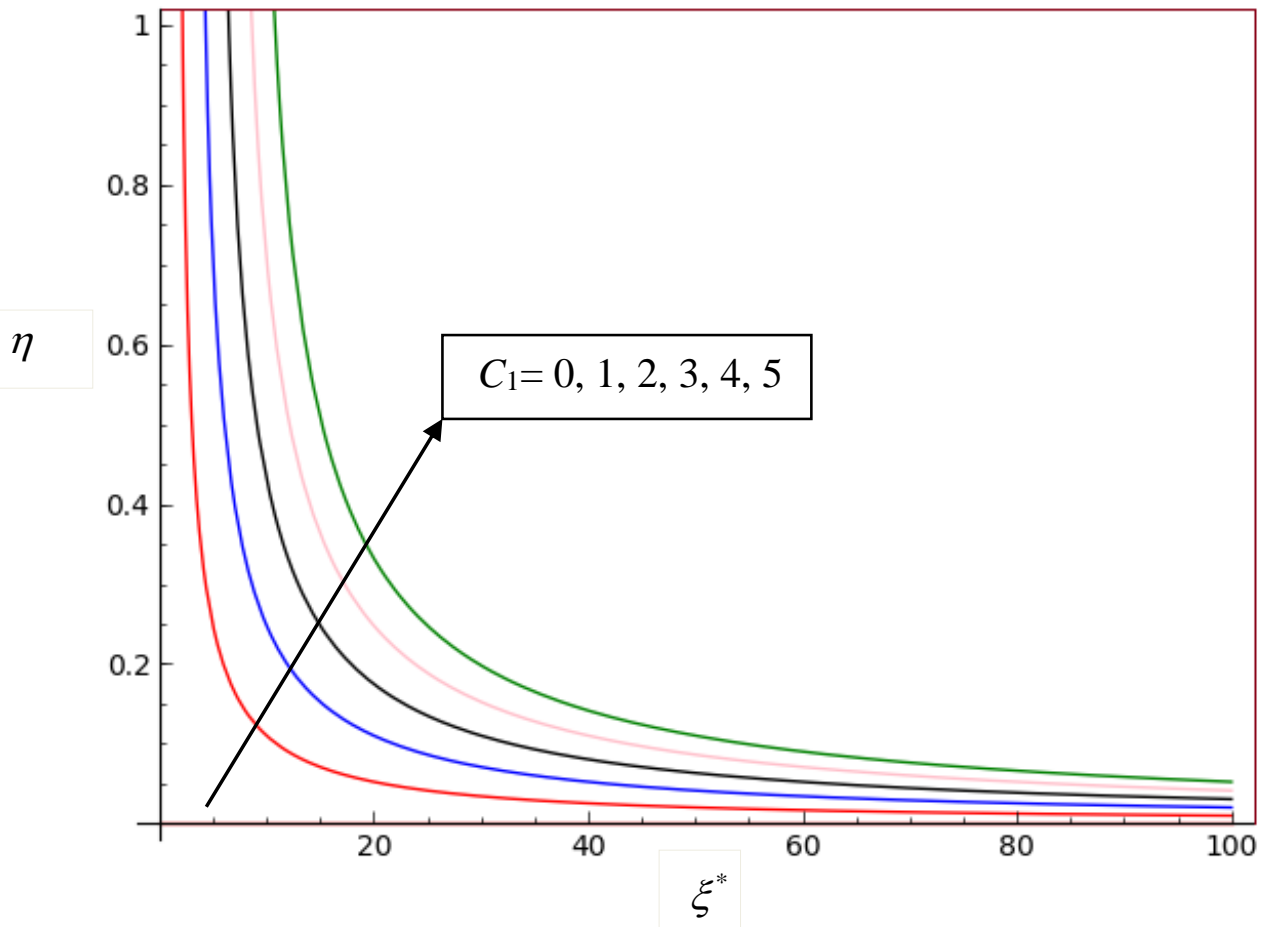

Figure 4a: Streamlines $\psi\left(\xi^{*}, \eta\right)=$ Constant- $C_{1}$ for different values of $C_{1}$ when $Q=1$ and $C=0.1$

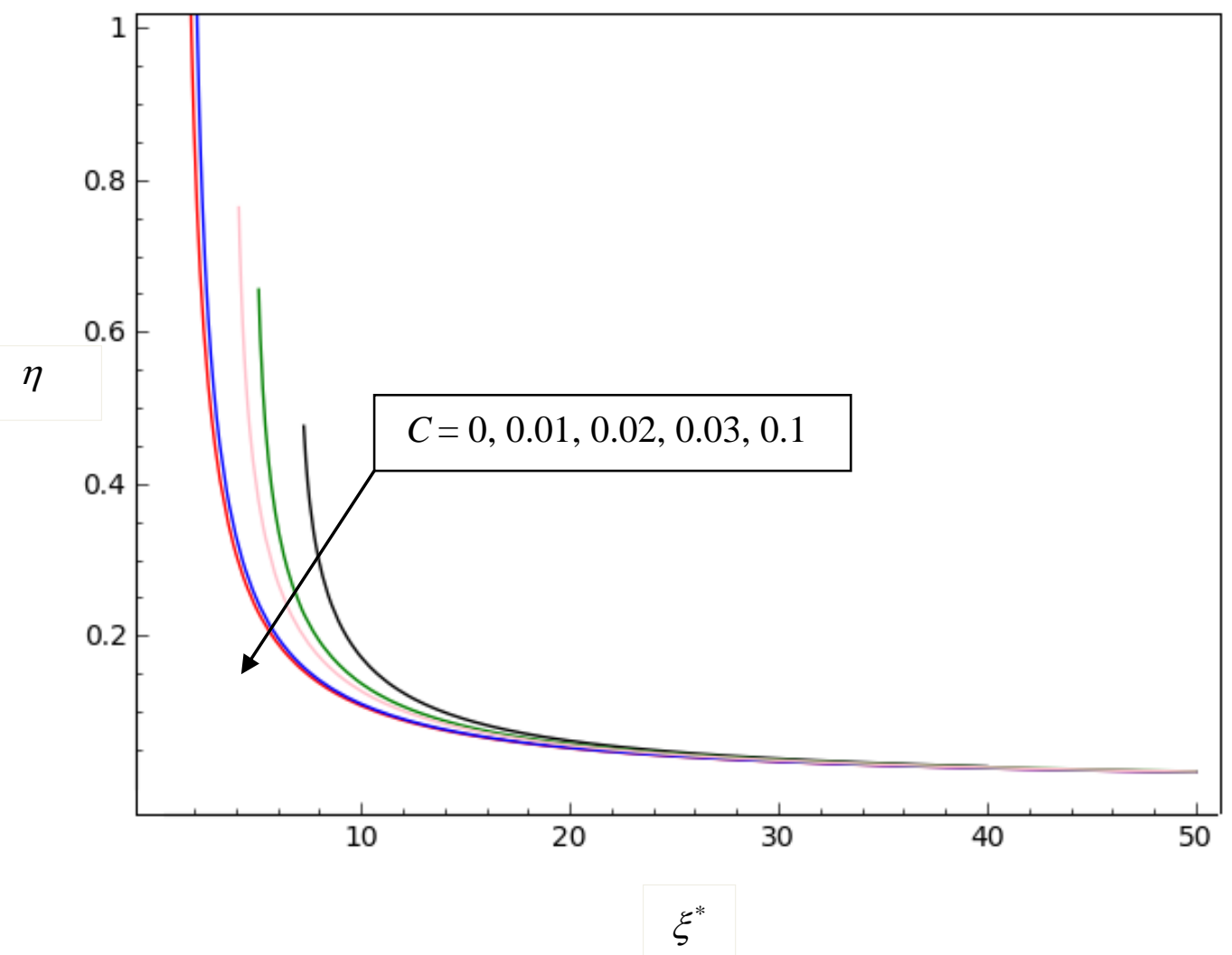

Figure 4b: Streamlines $\psi\left(\xi^{*}, \eta\right)=1$ for different values of $C$ when $Q=1$. 


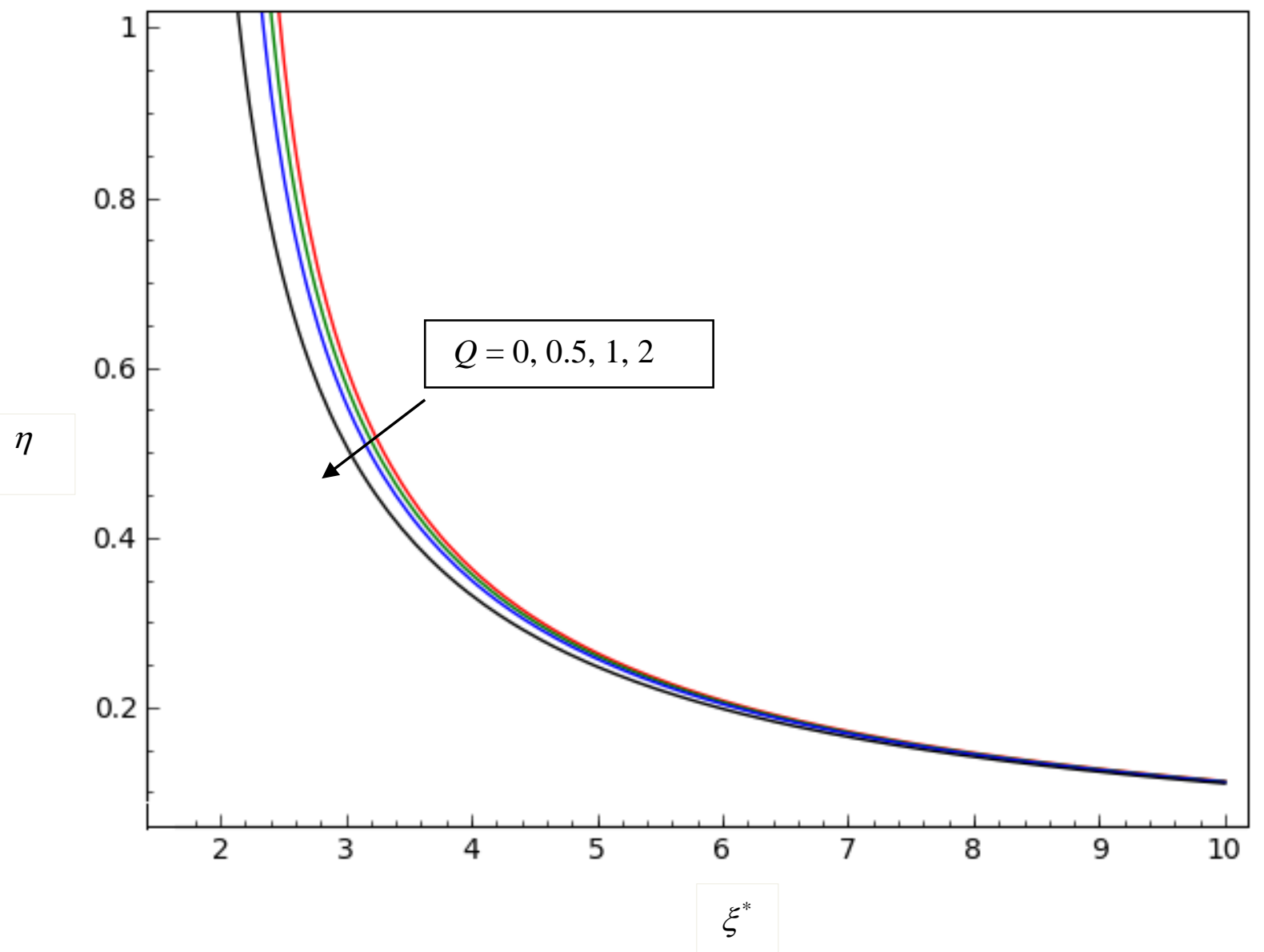

Figure 4c: Streamlines $\psi\left(\xi^{*}, \eta\right)=1$ for different values of $Q$ when $C=0.1$. 


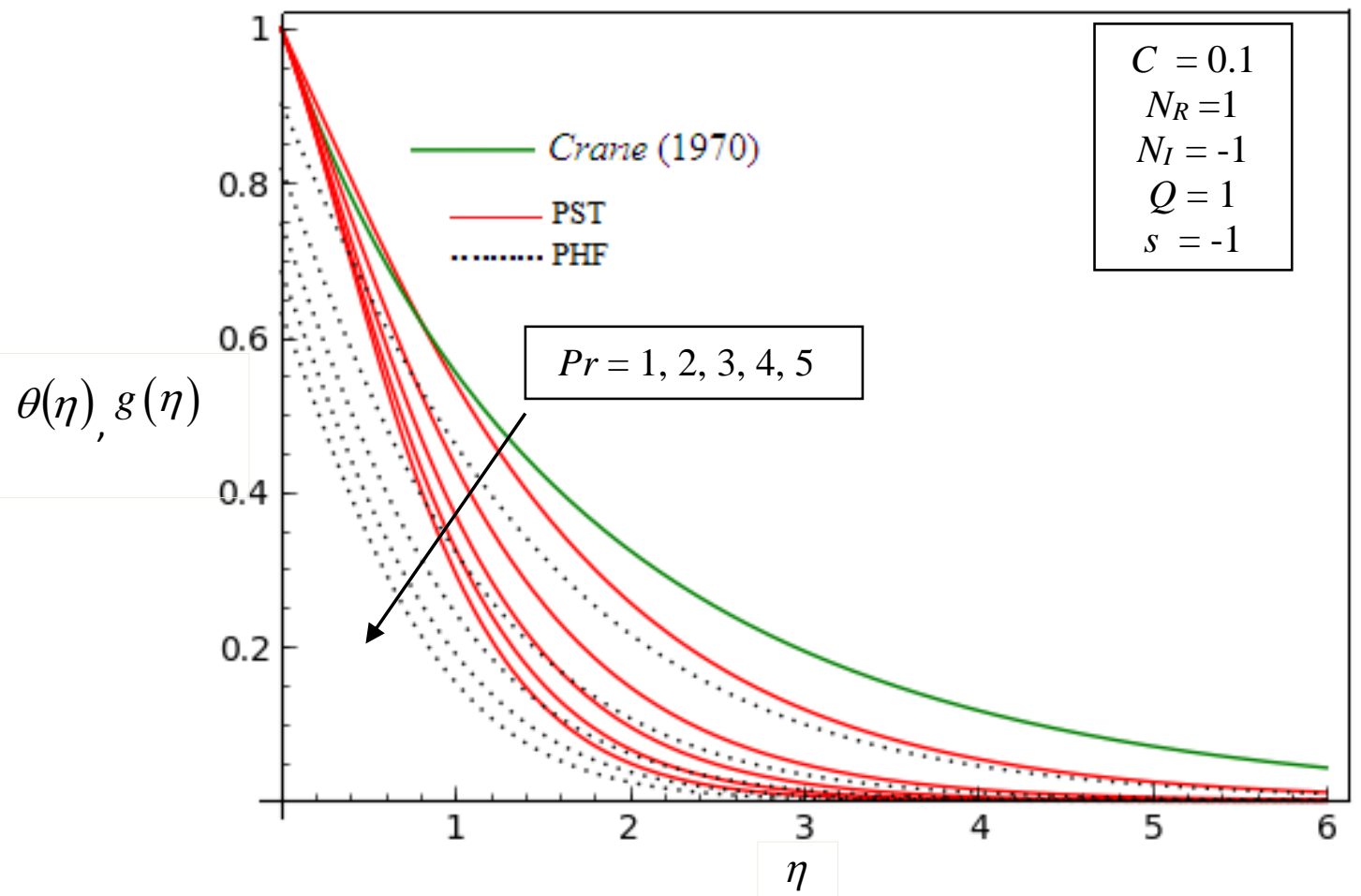

Figure 5:Variation of the non-dimensional temperature $\theta$ with $\eta$ the transformation co-ordinate normal to the surface for different values of Prandtl number $\operatorname{Pr}$ for the cases PST and PHF. 


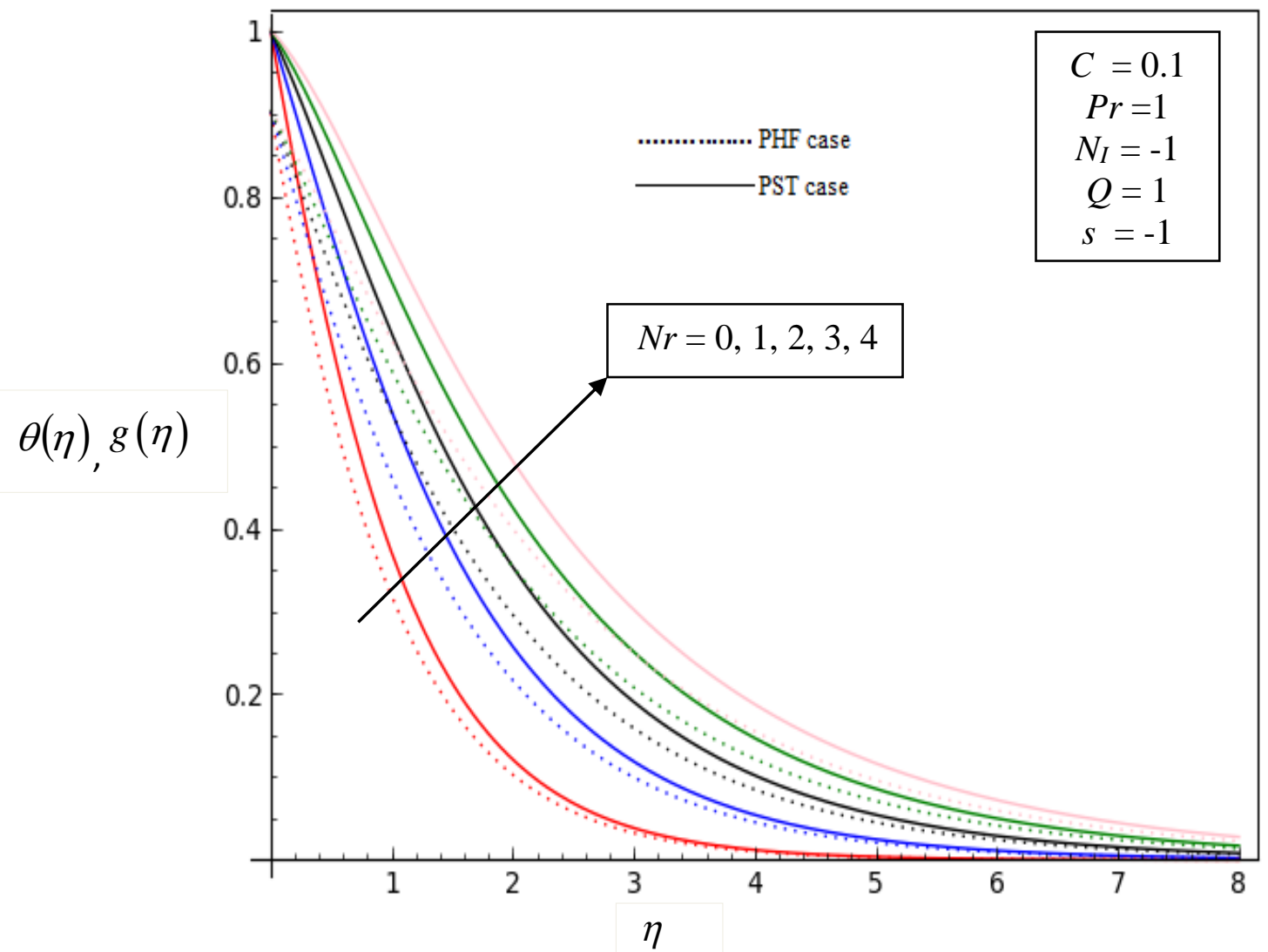

Figure 6:Variation of the non-dimensional temperature $\theta$ with $\eta$ the transformation co-ordinate normal to the surface for different values of radiation number $\mathrm{Nr}$ for the cases PST and PHF. 


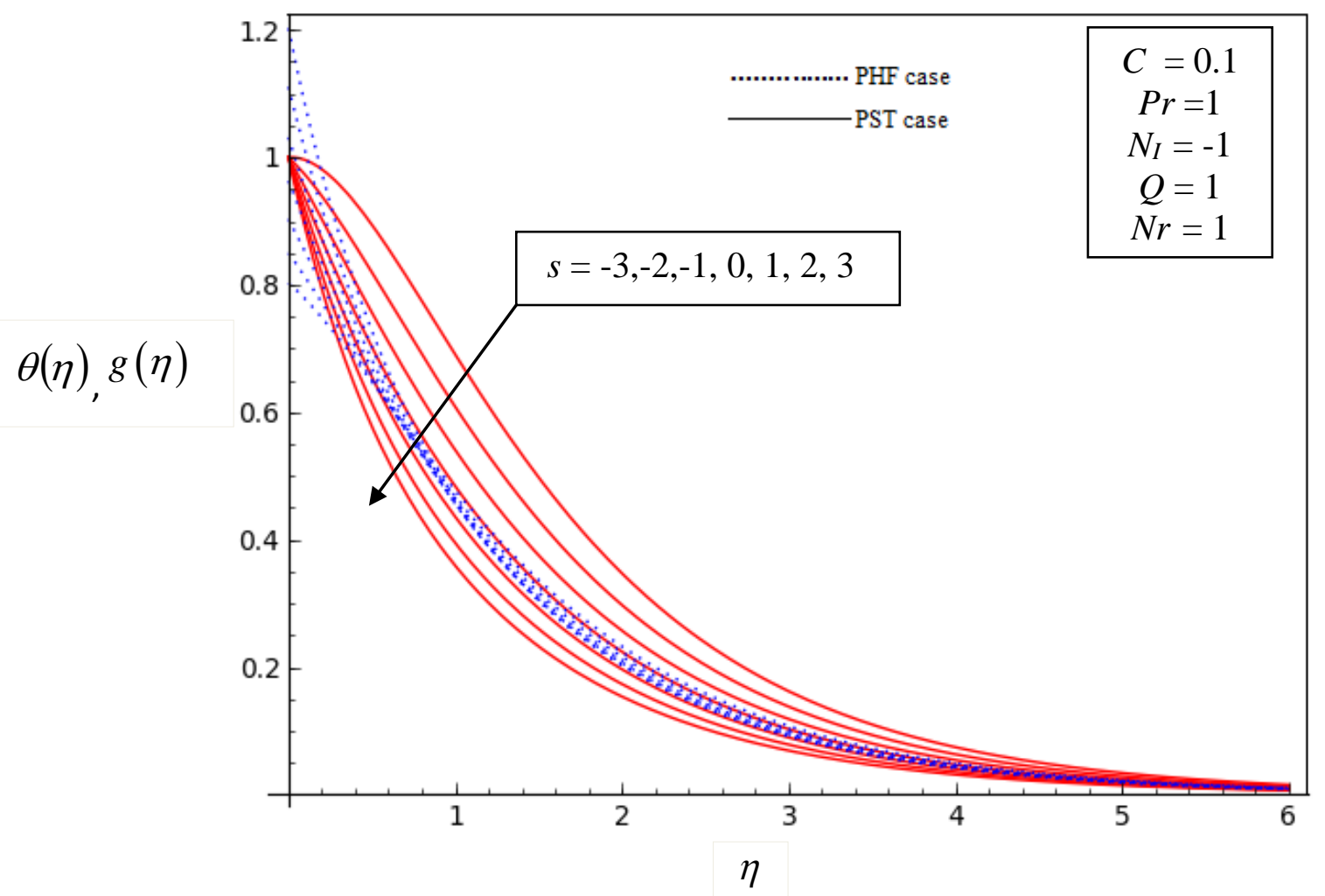

Figure 7:Variation of the non-dimensional temperature $\theta$ with $\eta$ the transformation co-ordinate normal to the surface for different values of wall temperature parameter $s$ for the cases PST and PHF. 


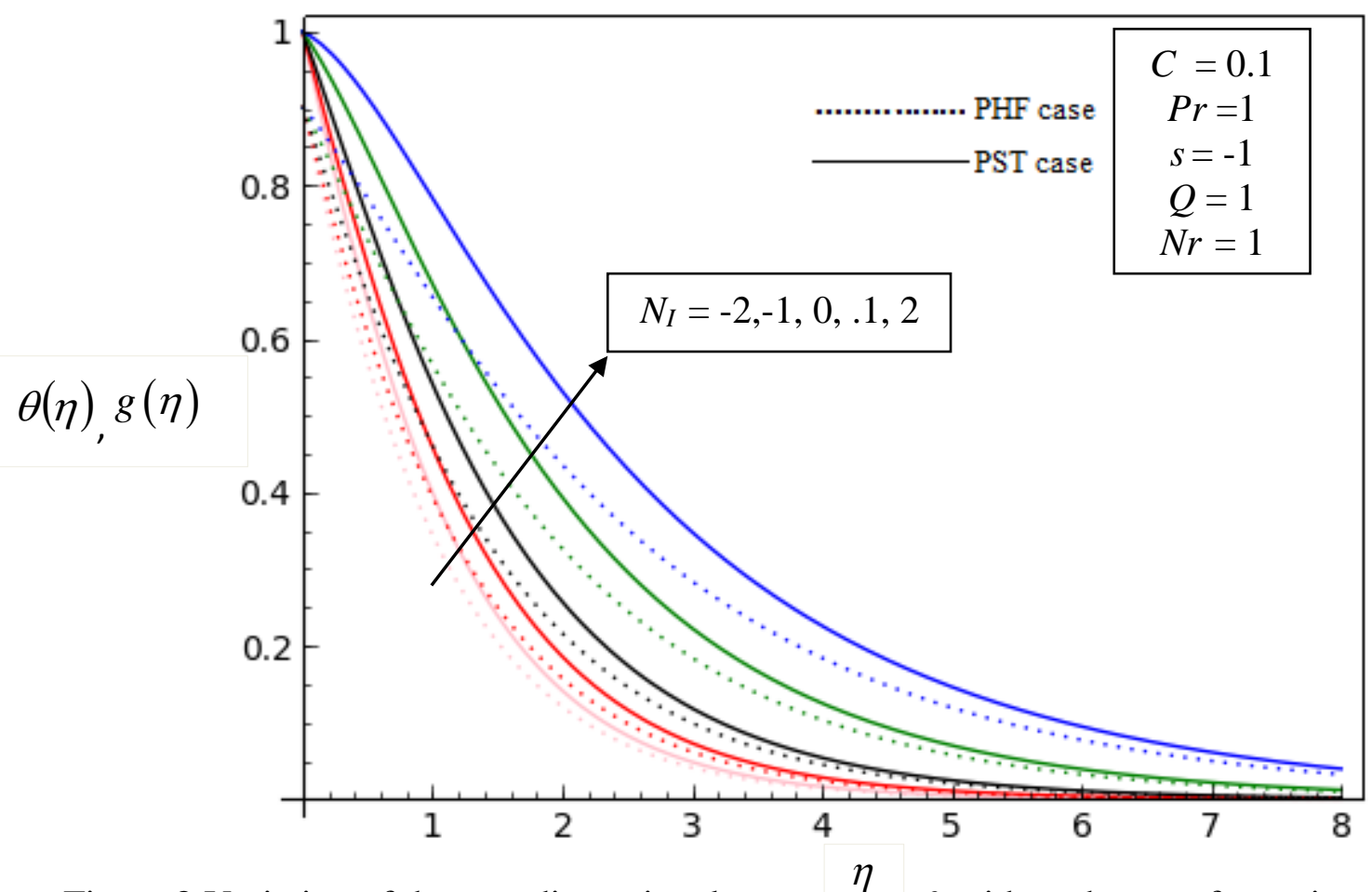

Figure 8:Variation of the non-dimensional temperature $\theta$ with $\eta$ the transformation co-ordinate normal to the surface for different values of heat source/sink parameter $N_{I}$ for the cases PST and PHF. 


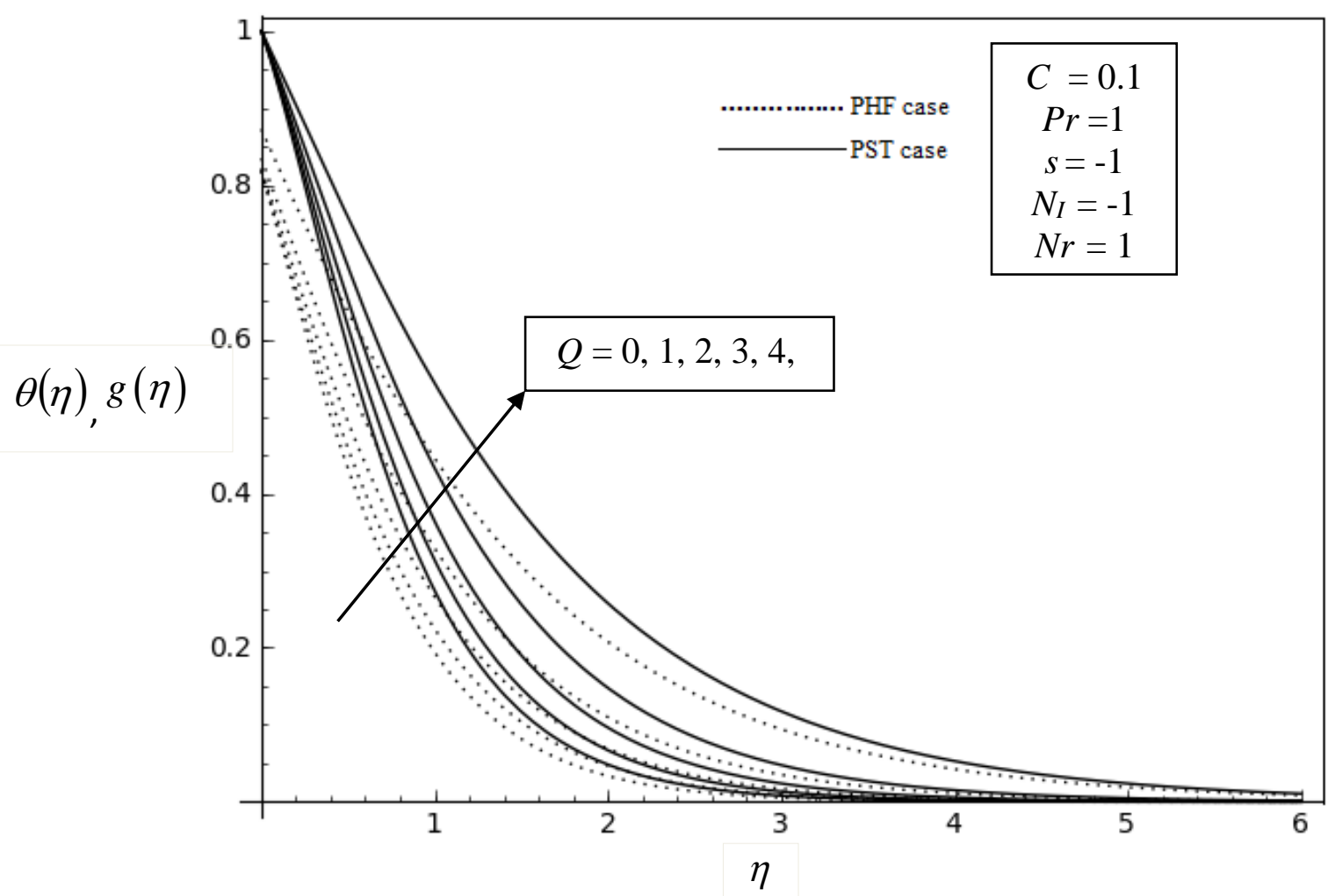

Figure 9:Variation of the non-dimensional temperature $\theta$ with $\eta$ the transformation co-ordinate normal to the surface for different values of Chandrasekhar number $Q$ or the cases PST and PHF. 


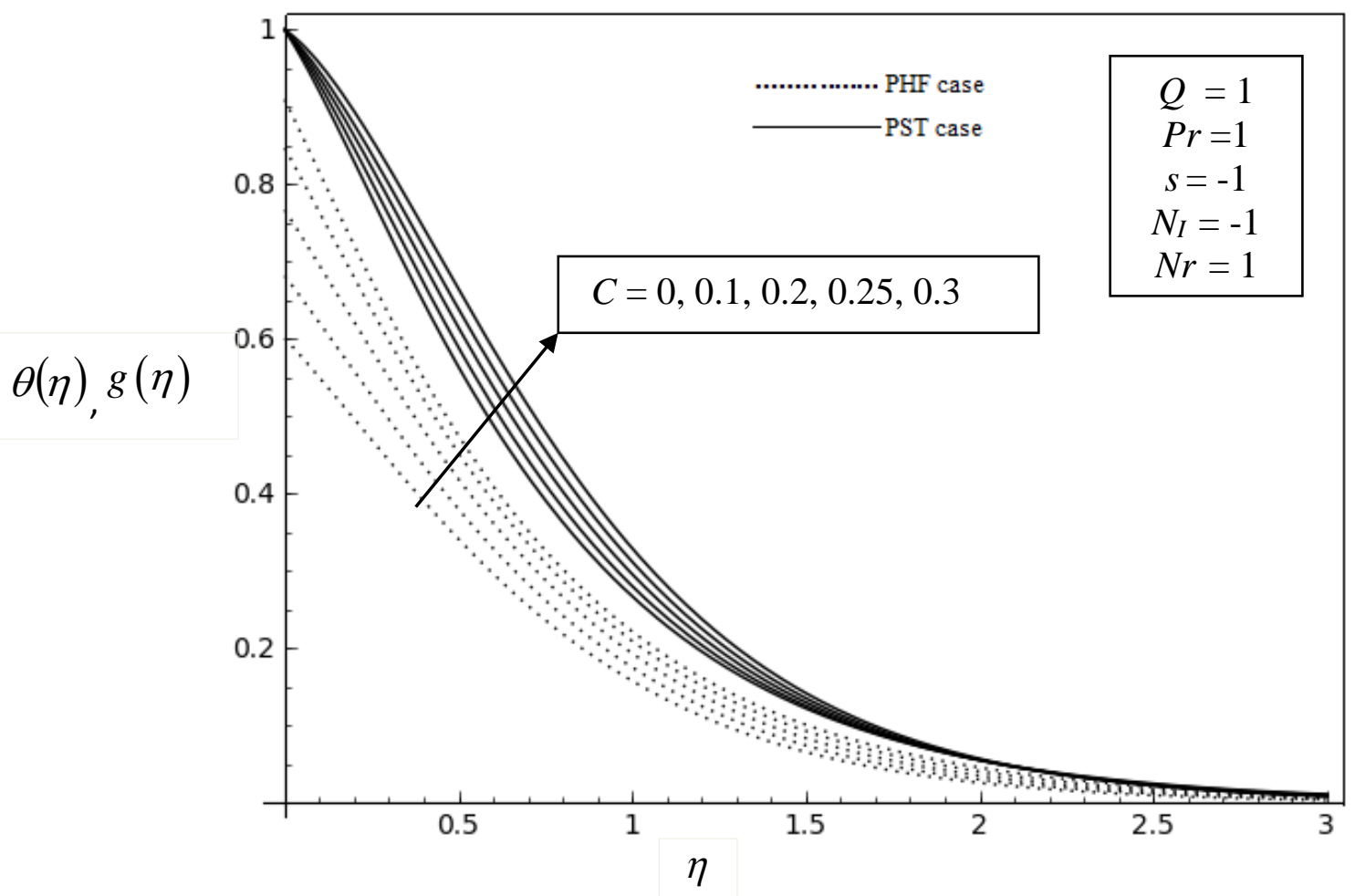

Figure 10: Variation of the non-dimensional temperature $\theta$ with $\eta$ the transformation co-ordinate normal to the surface for different values of couple stress parameter $C$ for the cases PST and PHF. 
Table 1: Illustrating the variation of $-f^{\prime \prime}(0)$ with $C$ and $Q$ for the flow over stretching sheet.

\begin{tabular}{|c|c|c|}
\hline$C=0.01$ & $Q$ & $-f_{\eta \eta}(0)$ \\
\hline \multirow{7}{*}{} & 0 & 9.94936 \\
& 1 & 9.89739 \\
& 2 & 9.84399 \\
& 3 & 9.8176 \\
& 5 & 9.7891 \\
\hline$Q=1$ & $C$ & $-f_{\eta \eta}(0)$ \\
\hline & 0 & 1.41421 \\
& 0.1 & 2.68999 \\
& 0.01 & 4.21260 \\
& 0.05 & 9.89739 \\
\hline
\end{tabular}


Table 2: Values of wall temperature gradient - $\theta_{\eta}(0)$ (PST case) and wall temperature $g(0)$ (PHF case) for different values of $C, N_{R}, \operatorname{Pr}, Q, s$ and $N_{I}$.

\begin{tabular}{|c|c|c|c|c|c|c|c|}
\hline$C$ & $N_{R}$ & Pr & $Q$ & $N_{I}$ & $s$ & $-\theta_{\eta}(0)$ & $g(0)$ \\
\hline $\begin{array}{c}0.0 \\
0.01 \\
0.1\end{array}$ & 1.0 & 2.0 & 1.0 & 0.05 & 2.0 & $\begin{array}{l}1.51787 \\
1.23460 \\
1.18187\end{array}$ & $\begin{array}{l}0.674689 \\
0.519563 \\
0.508058\end{array}$ \\
\hline 0.1 & $\begin{array}{l}1.0 \\
3.0 \\
5.0\end{array}$ & 4.0 & 1.0 & 0.05 & 2.0 & $\begin{array}{l}2.03623 \\
1.83466 \\
1.78131\end{array}$ & $\begin{array}{l}0.516917 \\
0.519868 \\
0.518986\end{array}$ \\
\hline 0.1 & 2.0 & $\begin{array}{l}2.0 \\
4.0 \\
6.0\end{array}$ & 1.0 & 0.05 & 2.0 & $\begin{array}{l}1.17529 \\
1.89900 \\
2.40763\end{array}$ & $\begin{array}{l}0.783120 \\
0.519659 \\
0.435544\end{array}$ \\
\hline 0.1 & 2.0 & 4.0 & $\begin{array}{l}0.0 \\
2.0 \\
3.0\end{array}$ & 0.05 & 2.0 & $\begin{array}{l}1.83706 \\
1.98990 \\
2.02238\end{array}$ & $\begin{array}{l}0.522181 \\
0.511978 \\
0.477179\end{array}$ \\
\hline 0.1 & 2.0 & 4.0 & 1.0 & $\begin{array}{l}-0.05 \\
0.0 \\
0.05\end{array}$ & 2.0 & $\begin{array}{l}1.97488 \\
1.94252 \\
1.89000\end{array}$ & $\begin{array}{l}0.478315 \\
0.478134 \\
0.475327\end{array}$ \\
\hline 0.1 & 2.0 & 4.0 & 1.0 & 0.05 & $\begin{array}{l}1.0 \\
2.0 \\
3.0\end{array}$ & $\begin{array}{l}0.89567 \\
1.89000 \\
1.92658\end{array}$ & $\begin{array}{c}0.39876 \\
0.475327 \\
0.53267\end{array}$ \\
\hline
\end{tabular}

